\title{
Article \\ Curing through Ceramics: Influence of Different Light-Curing Units and Curing Modes on Bond Strength
}

\author{
Evonne Mei Jing Phua, John Neil Waddell (1) and Joanne Jung Eun Choi * (i) \\ Sir John Walsh Research Institute, Faculty of Dentistry, University of Otago, Dunedin 9016, New Zealand; \\ phuev443@student.otago.ac.nz (E.M.J.P.); neil.waddell@otago.ac.nz (J.N.W.) \\ * Correspondence: joanne.choi@otago.ac.nz
}

check for updates

Citation: Phua, E.M.J.; Waddell, J.N.; Choi, J.J.E. Curing through Ceramics: Influence of Different Light-Curing Units and Curing Modes on Bond Strength. Oral 2022, 2, 62-74. https://doi.org/10.3390/ oral2010008

Received: 27 December 2021 Accepted: 15 February 2022 Published: 17 February 2022

Publisher's Note: MDPI stays neutral with regard to jurisdictional claims in published maps and institutional affiliations.

Copyright: (C) 2022 by the authors. Licensee MDPI, Basel, Switzerland. This article is an open access article distributed under the terms and conditions of the Creative Commons Attribution (CC BY) license (https:// creativecommons.org/licenses/by/ $4.0 /)$.

\begin{abstract}
Objectives: To measure and compare the bond strength between three different types of ceramics and resin cement, as well as the degree of conversion of resin cement after using different light-curing units and curing modes. Methods: Three types of ceramics-Leucite-reinforced (Empress CAD), Lithium disilicate (Emax CAD), and Zirconia (Emax ZirCAD)—of varying thicknesses (1.5 mm and $2.0 \mathrm{~mm}$ ) were bonded to a light-cure resin cement (Variolink Esthetic LC). Light-curing was carried out using a monowave LCU (3M Elipar DeepCure-S LED Curing Light with irradiance of $1470 \mathrm{~mW} / \mathrm{cm}^{2}$ ) and with polywave LCU (Ivoclar Bluephase PowerCure) using High, Turbo, and $3 \mathrm{~s}$ curing modes, respectively $\left(1200,2100,3000 \mathrm{~mW} / \mathrm{cm}^{2}\right)$. A chevron-notch bond strength test (total $n=288)$ was conducted to calculate the fracture energy and interfacial bond strength $\left(\mathrm{J} / \mathrm{m}^{2}\right)$. The degree of cure $(\% \mathrm{DC})$ of the residual resin cement on debonded surfaces was measured using Fourier Transform Infrared Spectroscopy (FTIR). Collected data were statistically analysed under SPSS ver. 27 by conducting an ANOVA and Bonferroni post hoc test. The mode of failure was established using a scanning electron microscope (SEM). Results: A significant difference in interfacial bond strength was found between the three types of ceramic material groups $(p<0.01)$. Cement cured through Empress that was $2 \mathrm{~mm}$ thick showed the highest bond strength $\left(1.36 \pm 0.46 \mathrm{~J} / \mathrm{m}^{2}\right)$, while the lowest was observed $\left(0.26 \pm 0.07 \mathrm{~J} / \mathrm{m}^{2}\right)$ in $2 \mathrm{~mm}$ Emax CAD using the $3 \mathrm{~s}$ mode. The use of different LCUs and curing modes had a significant influence on the \%DC of resin cement seen in all groups, except $2 \mathrm{~mm}$ Emax ZirCAD. The dominant mode of failure for Empress, EmaxCAD, and EmaxZirCAD were cohesive, adhesive, and mixed, respectively. Conclusions: The type of ceramic and its thickness can significantly affect bond strength, and the results showed that polywave LCU is more effective than monowave LCU when curing through ceramics.
\end{abstract}

Keywords: photopolymerisation; ceramic; adhesion; resin cements; degree of cure; bond strength

\section{Introduction}

The change from traditional full-gold crowns and porcelain-fused-to-metal (PFM) to all-ceramic restorations over the past few decades is considered to be one of the fastest paradigm shifts in restorative dentistry $[1,2]$. Today, the prevalence of all-ceramic restorations is recorded at 80.2\% [3], 69\% [4] and 57.7\% [5] in the United States of America (USA), United Kingdom (UK) and New Zealand (NZ), respectively. These surveys showed that more than half of the population in these countries prefer all-ceramic restorations, highlighting the increasing popularity of ceramics as a restorative material. Dental ceramics are known to many clinicians as an ideal biomaterial because of its biocompatibility, inertness, and excellent aesthetic quality [6]. In modern dentistry, the rapid advances and success of Computer-Aided Design and Computer-Aided Manufacturing (CAD/CAM) technology coupled with the high public desire for tooth-coloured restorations, justify the continuous demand and manufacture of all-ceramic restorations [7].

A recent survey concluded that the most common complication of all-ceramic restorations is debonding, reporting up to $52 \%$ amongst other restorative failures [8]. A stable bond 
between all-ceramic restorations and the underlying prepared tooth structure is strongly influenced by the degree of cure of resin cement [9]. If resin cement is under-cured, it remains primarily in a monomeric state which is prone to washout, leading to an increase in microleakages of oral contaminants. When resin cement is well-photopolymerised, both its mechanical and chemical properties significantly improve [9-12], resulting in remarkably low solubility, high dimensional stability, better colour stability, and greater compressive and tensile strength [13].

The light-emitting diode (LED) light-curing unit (LCU) is considered to be the gold standard in contemporary dentistry [14]. Each generation of LED LCU emits its own irradiance power and wavelength spectrum, which should match the light absorption spectrum of photoinitiators in resin-based materials [9,14-16]. The first generation of LED LCU had low irradiance of $400 \mathrm{~mW} / \mathrm{cm}^{2}$, while the second generation of LED LCU improved by increasing its irradiance up to $1000 \mathrm{~mW} / \mathrm{cm}^{2}$ [17]. However, both generations utilise the same monowave technology (single-peak), emitting a narrow range of wavelengths, resulting in the inability to light-cure restorative materials using photoinitiators of shorter wavelength [17]. Today, third-generation LED LCU use polywave technology (dual-peak), which is set to emit more than one wavelength peak. The incorporation of an array of blue and violet diodes within the LCU results in a broad spectral range of light emission. This allows a new generation of LCU to adequately cure all types of dental resin products on the market $[9,17]$. The newly designed polywave LED LCU features multiple curing modes based on the material and indication. The ' $3 \mathrm{sec}^{\prime}$, 'turbo', and 'high' modes produce high irradiance of up to $3000 \mathrm{~mW} / \mathrm{cm}^{2}$, enabling short curing times of 3,5 , and $10 \mathrm{~s}$, respectively. The manufacturer claims that a shorter curing time helps reduce chairside time and excess heat exposure to the pulp.

Currently, there is a scarcity of peer-reviewed reports concerning which light-curing units and curing modes are suitable to cure resin cement underneath different ceramic materials. The existing evidence mainly reports findings on either one type of ceramic material or one particular type of LCU technology, with the majority of studies testing the influences of thickness and shade of ceramic material [12,18-26]. This lack of research on the efficacy of different light-curing technologies on indirect restorations makes it inconclusive to give any clinical recommendations. Therefore, the current study aims to investigate the influence of different light-curing units (monowave and polywave) and their curing modes on the bond strength between resin cement and three different popular dental ceramic restorative materials (leucite-reinforced, lithium disilicate and zirconia), as well as the degree of conversion of resin cement. The findings from this project have the potential to serve as the first guideline for dental practitioners in regard to the best LCU for indirect restorations. The null hypotheses state that there is no significant effect on the interfacial bond strength degree of conversion of resin cement when polymerised (1) using different LCUs and curing modes; and (2) under different ceramic types and thicknesses.

\section{Material and Methods}

\subsection{Specimen Preparation}

In order to calculate an adequate sample size, the $G^{*}$ Power Software (Version 3.1, Universität Düsseldorf, Düsseldorf, Germany) was used, and a sample size of 12 per group resulted in a statistical power of $95 \%$. Three types of ceramic blocks-that is, leucitereinforced (Empress CAD, Ivoclar Vivadent, Schaan, Liechtenstein), lithium disilicate (Emax CAD, Ivoclar Vivadent, Schaan, Liechtenstein), and zirconia (Emax ZirCAD, Ivoclar Vivadent, Schaan, Liechtenstein)—of the same shade (A2) and translucency (HT- high translucency) were sectioned into slices of $1.5 \mathrm{~mm}$ and $2.0 \mathrm{~mm}$ thicknesses using a cutting machine (Accutom-50, Struers, Copenhagen, Denmark) ( $n=12$ per sample group). The lithium disilicate and zirconia slices were sintered in furnaces (Programmat P500/G2, Ivoclar Vivadent and Ceramill Therm II, Amann Girrbach, Pforzheim, Germany) as per the manufacturer's instructions. The leucite-reinforced and sintered lithium disilicate slices were then pre-treated with 9\% buffered hydrofluoric acid (Porcelain Etch, Ultradent, South 
Jordan, USA) for $1 \mathrm{~min}$ and $20 \mathrm{~s}$, respectively. The sintered zirconia slices were sandblasted at 1.5 bar pressure with $100 \mu \mathrm{m}$ aluminium oxide $\left(\mathrm{Al}_{2} \mathrm{O}_{3}\right)$. After thoroughly rinsing the slices under running tap water, a thin coat of silane coupling agent (Monobond Plus, Ivoclar Vivadent) was applied using a microbrush and allowed to react for $1 \mathrm{~min}$ before dispersing the excess with a strong stream of air.

Chevron notch-shaped stickers of $4 \mathrm{~mm} \times 4 \mathrm{~mm}$ (Teflon) were placed on each of the ceramic slices to isolate the bonding area (Figure 1a). Light-cured resin cement (Variolink Esthetic LC, Ivoclar Vivadent) was directly injected onto the 3D-printed acrylic beams $(5 \mathrm{~mm} \times 4 \mathrm{~mm} \times 15 \mathrm{~mm})$ (Figure 1b). The face of the beam being bonded to the ceramic was printed with a $3 \mathrm{~mm} \times 3 \mathrm{~mm} \times 1.5 \mathrm{~mm}$ recess to provide additional mechanical retention at the beam/cement interface to ensure that the failure was directed to the ceramic/cement interface where only the area of the chevron notch was bonded. The beams were bonded onto the prepared ceramic slices by careful positioning over the chevron sticker using a 3D-printed customized jig to ensure the beam was always placed perpendicular to the ceramic slice. After firm finger pressure was applied, the excess resin cement was removed using a microbrush. The ceramic slice was then fitted on top of a customized jig, and the LCU was placed underneath via the jig (Figure 1c), light-curing the resin cement through the ceramic slice (Figure 1d).

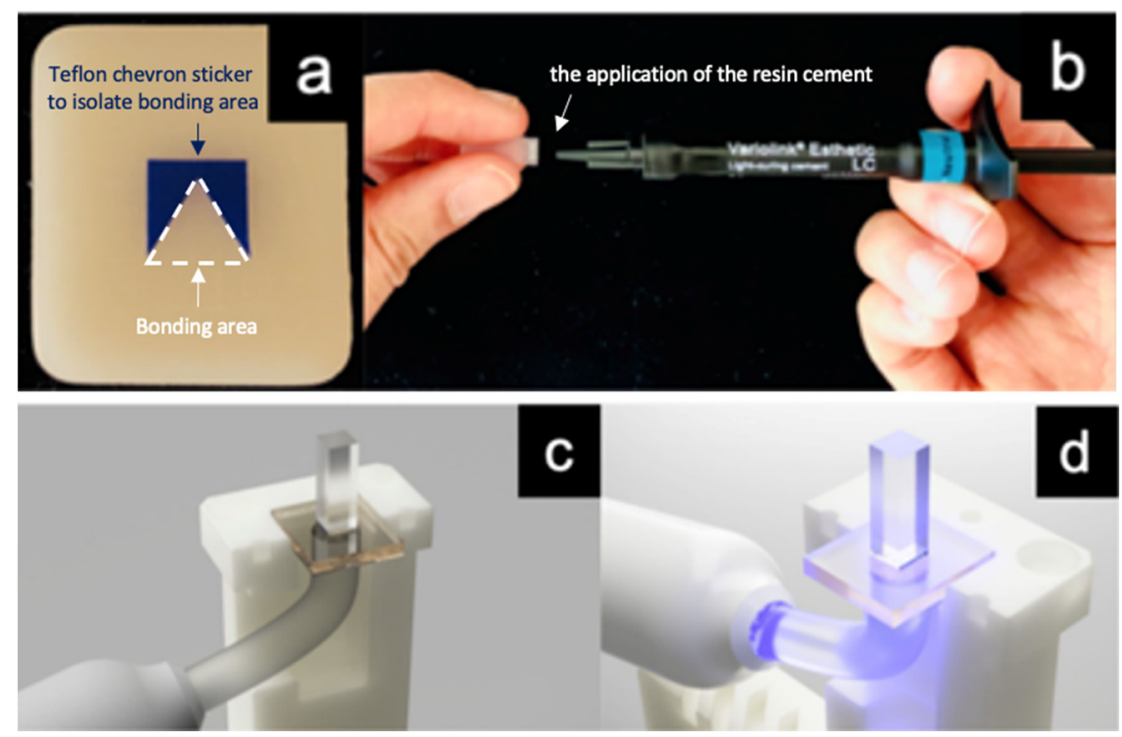

Figure 1. Preparation of specimens for the chevron notch bond strength test, showing (a) the chevron notch sticker applied to the face of the ceramic, (b) the application of the resin cement to the bonding surface of the beam prior to positioning the beam over the chevron notch, (c) and subsequently light-curing using a jig (d) to control the positioning of the light-curing tip.

\subsection{Light Curing}

The resin cement for of the sample groups was light-cured using one of the following protocols: monowave LED LCU (Elipar DeepCure Paradigm, 3M) in standard mode $\left(1470 \mathrm{~mW} / \mathrm{cm}^{2}\right)$ for $10 \mathrm{~s}$, polywave LED LCU (Bluephase PowerCure, Ivoclar Vivadent) in high mode $\left(1200 \mathrm{~mW} / \mathrm{cm}^{2}\right)$, turbo mode $\left(2100 \mathrm{~mW} / \mathrm{cm}^{2}\right)$, and $3 \mathrm{~s}$ mode $\left(3000 \mathrm{~mW} / \mathrm{cm}^{2}\right)$ for 10,5 , and 3 s, respectively (Table 1). The LCUs were orientated accordingly and supported using a silicone putty material to ensure a constant distance between the light-curing unit tip and the ceramic material (Figure 2). 
Table 1. Different types of LCU and curing modes with their respective irradiance and curing modes.

\begin{tabular}{ccccc}
\hline Type of LCU & Monowave & \multicolumn{3}{c}{ Polywave } \\
\hline Curing Modes & - & High & Turbo & $3-\mathrm{s}$ \\
Irradiance $\left(\mathrm{W} / \mathrm{cm}^{2}\right)$ & 1470 & 1200 & 2100 & 3000 \\
Curing time $(\mathrm{s})$ & 10 & 10 & 5 & 3 \\
\hline
\end{tabular}

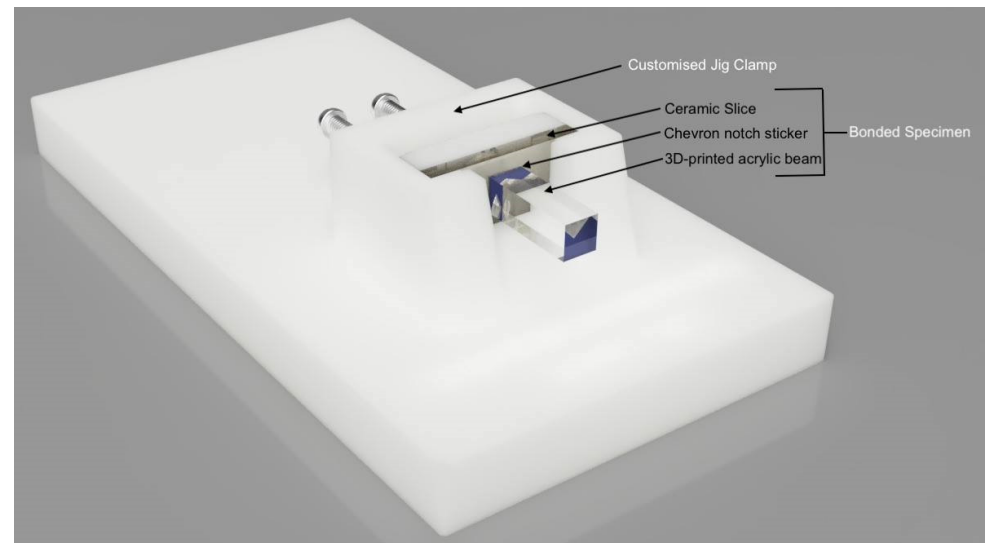

Figure 2. Image showing assembly of bonded specimen to the customised jig clamp before being loaded by a universal testing machine.

\subsection{Interfacial Bond Strength Test}

The bonded specimens were clamped on a customised jig and loaded $13 \mathrm{~mm}$ from the bonded interface (Figure 2). A universal testing machine (Instron 3369, Instron, Norwood, MA, USA) was used to apply a $50 \mathrm{~N}$ load cell at a cross-head speed of $0.05 \mathrm{~mm} / \mathrm{min}$ until failure occurred. The interfacial bond strengths $\left(\mathrm{G}_{\mathrm{IC}}\right)$ were calculated using the formula (Figure 3) [27]:

$$
\mathrm{G}_{\mathrm{IC}}\left(\mathrm{J} / \mathrm{m}^{2}\right)=\frac{104.5 F^{2} L^{3}}{E D^{6}}
$$

where:

$F=$ load at failure $(\mathrm{N})$

$L=$ distance from bonded interface to loading point

$E=$ elastic modulus of 3D-printed beam (4.16 GPa)

$D=$ cross sectional area of $3 \mathrm{D}$-printed beam

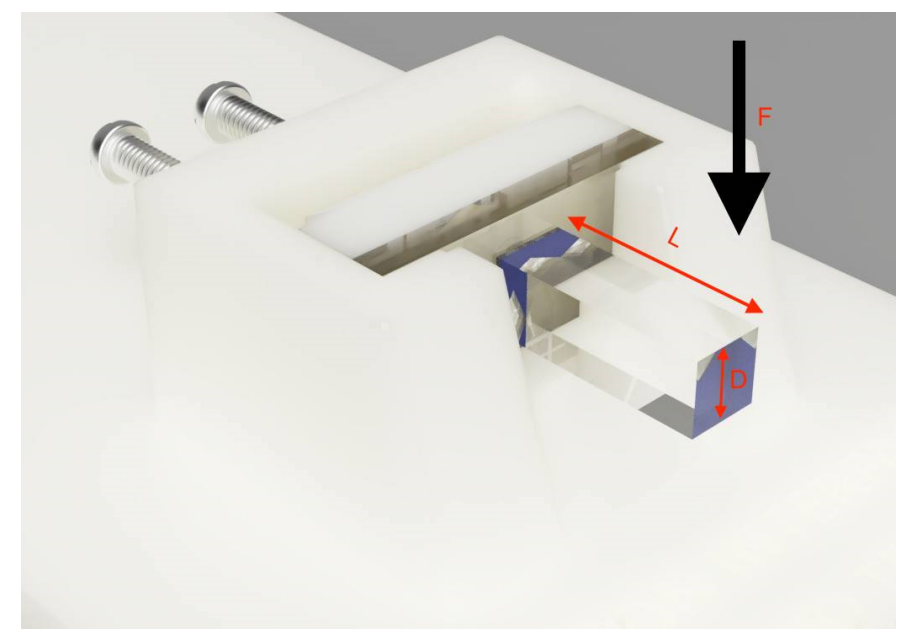

Figure 3. Image showing a schematic illustration of a bonded specimen in load configuration. 


\subsection{Degree of Conversion (DC)}

A portion of the recently cured resin cement from the failure interface was scrapped out and placed on the ATR-FTIR (Bruker, Billerica, MA, USA) operating from 400 to $4000 \mathrm{~cm}^{-1}$ to measure the degree of conversion (DC). The number of double-carbon bonds that are converted into single bonds provides the DC (\%) of the resin cement. The percentage of unreactive carbon-carbon double bonds $(\% \mathrm{C}=\mathrm{C})$ was determined from the ratio of the absorbance intensity of aliphatic $C-C$ (peak $1637 \mathrm{~cm}^{-1}$ ) to that of aromatic $C=C$ (peak at $\left.1608 \mathrm{~cm}^{-1}\right)$.

The DC was then calculated using the formula [12]:

$$
\operatorname{DC}(\%)=\left[1-\frac{\left(1637 \mathrm{~cm}^{-1} / 1608 \mathrm{~cm}^{-1}\right) \text { Peak height after curing }}{\left(1637 \mathrm{~cm}^{-1} / 1608 \mathrm{~cm}^{-1}\right) \text { Peak height before curing }}\right] \times 100
$$

\subsection{Mode of Failure and Surface Analysis}

Each debonded specimen was examined under a light microscope (Nikon SMZ800N, Tokyo, Japan) to determine the mode of failure. A representative sample from each group was then further analysed under a scanning electron microscope (SEM) (JSM-6700F, JEOL Ltd., Tokyo, Japan) at higher magnification $(25 \times-500 \times)$ and resolution. The mode of failure was classified into three categories: adhesive (failure between resin cement and ceramic), cohesive (failure within resin cement), and mixed (both adhesive and cohesive).

\subsection{Statistical Analysis}

The collected data of interfacial bond strength and \%DC were individually analysed using SPSS (version 27, IMB, New York, NY, USA), conducting a one-way ANOVA, with statistical difference set at $p<0.05$. The Bonferroni post hoc test was performed to determine differences among groups. Descriptive analysis was used to record the mode of failure.

\section{Results}

\subsection{Interfacial Bond Strength}

The mean and standard deviation of interfacial bond strengths for each group are presented in Figure 4 and Table 2. Overall, a significant difference between the interfacial bond strength was found between the three types of ceramic material groups $(p<0.01)$. The group showing the highest bond strength was the Empress $2.0 \mathrm{~mm}$ PT group $\left(1.36 \pm 0.46 \mathrm{~J} / \mathrm{m}^{2}\right)$, while the EmaxCAD $2.0 \mathrm{~mm} \mathrm{P3}$ group resulted in the lowest bond strength $\left(0.26 \pm 0.07 \mathrm{~J} / \mathrm{m}^{2}\right)$. When comparing the influence of increasing ceramic thicknesses on the bond strength, significant differences were only observed in the EmaxCAD group, between $1.5 \mathrm{~mm}$ and $2.0 \mathrm{~mm}$. Within these specific thicknesses, the Empress $2.0 \mathrm{~mm}$ and EmaxCAD $1.5 \mathrm{~mm}$ groups demonstrated significant differences in bond strength when cured under different light-curing units and curing modes.

Table 2. Mean and standard deviation of interfacial bond strength $\left(\mathrm{J} / \mathrm{m}^{2}\right)$ test results.

\begin{tabular}{ccccccrcr}
\hline $\begin{array}{c}\text { Ceramic Type } \\
\text { Ceramic Thickness (mm) }\end{array}$ & \multicolumn{2}{c}{ Empress } & \multicolumn{2}{c}{ EmaxCAD } & \multicolumn{2}{c}{ EmaxZirCAD } \\
\hline LCUs \& Curing Modes & $\mathbf{1 . 5}$ & $\mathbf{2}$ & $\mathbf{1 . 5}$ & $\mathbf{2}$ & $\mathbf{1 . 5}$ & $\mathbf{2}$ \\
\hline & & & & & \\
M & $0.65 \pm 0.31$ & $0.47 \pm 0.21$ & $0.33 \pm 0.12$ & $0.27 \pm 0.12$ & $0.34 \pm 0.13$ & $0.45 \pm 0.16$ \\
PH & $0.87 \pm 0.33$ & $0.88 \pm 0.34$ & $1.11 \pm 0.57$ & $0.40 \pm 0.27$ & $0.35 \pm 0.14$ & $0.32 \pm 0.18$ \\
PT & $0.84 \pm 0.24$ & $1.36 \pm 0.46$ & $1.15 \pm 0.53$ & $0.31 \pm 0.08$ & $0.38 \pm 0.12$ & $0.39 \pm 0.14$ \\
P3 & $0.62 \pm 0.08$ & $0.82 \pm 0.26$ & $0.46 \pm 0.20$ & $0.26 \pm 0.07$ & $0.32 \pm 0.09$ & $0.30 \pm 0.13$ \\
\hline
\end{tabular}




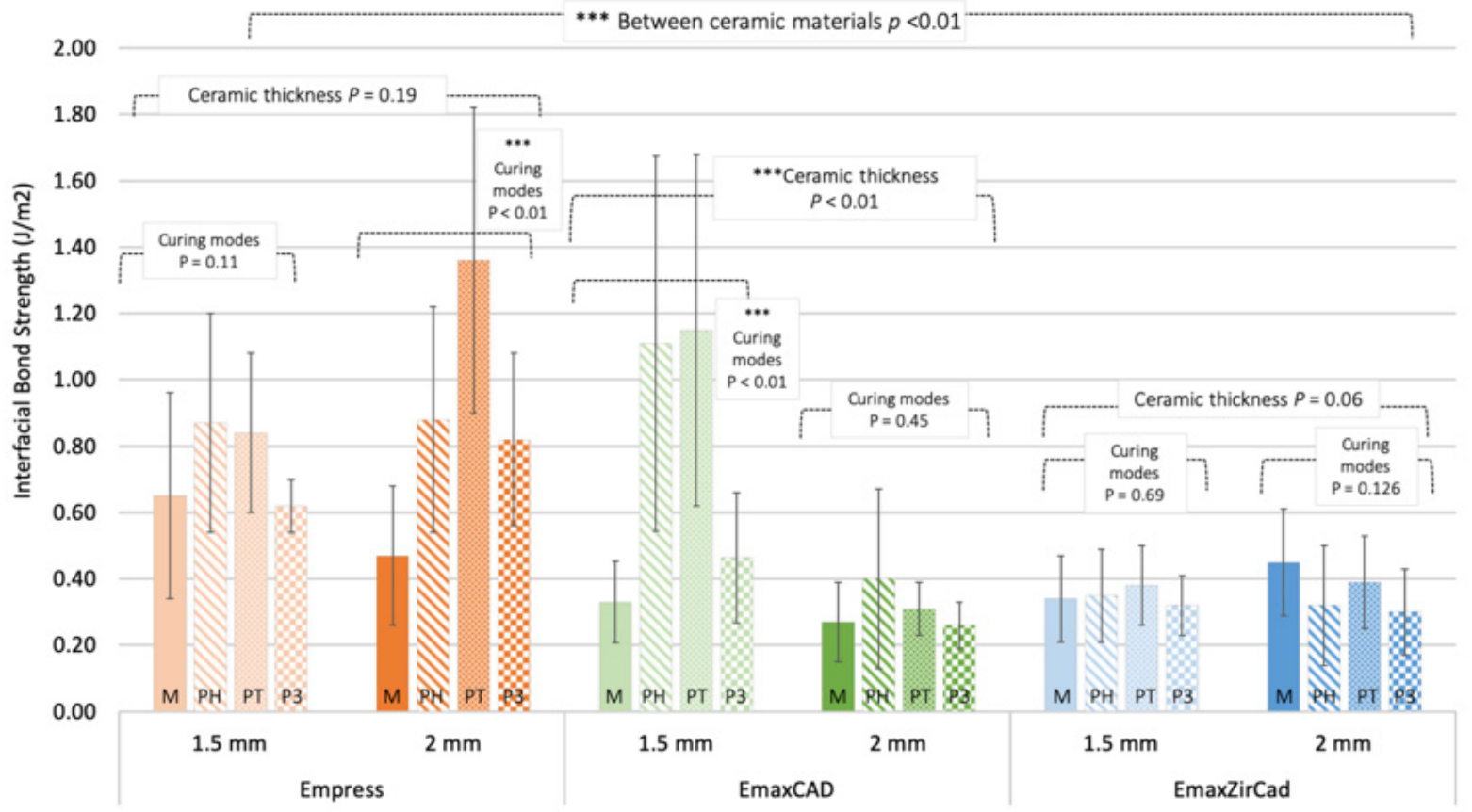

Figure 4. Bar chart plotting the mean and standard deviation of interfacial bond strength. (EmpressLeucitre-reinforced; EmaxCAD-Lithium disilicate; EmaxZirCAD-Zirconia) (M-monowave; PH-polywave-high mode; PT—polywave-turbo mode; P3-polywave-3 s mode). *** indicates statistical significance $p<0.01$.

\subsection{Degree of Cure}

The mean and standard deviation of DC of resin cement for each group are presented in Figure 5 and Table 3. Overall, no significant difference between the DC of resin cement was found between the three types of ceramic material groups $(p>0.01)$. The group showing the highest DC was the Empress $1.5 \mathrm{~mm}$ P3 group $(60.48 \pm 5.19 \%)$, while the EmaxZirCAD $1.5 \mathrm{~mm}$ P3 group resulted in the lowest cure degree (36.02 $\pm 8.46 \%)$. When comparing the influence of increasing ceramic thicknesses on bond strength, there were no significant differences between $1.5 \mathrm{~mm}$ and $2.0 \mathrm{~mm}$ for all ceramic types. Within these specific thicknesses, all groups demonstrated significant differences, except EmaxZirCAD $2.0 \mathrm{~mm}$, in the degree of cure of resin cement when cured under different light-curing units and curing modes.

Table 3. Mean and standard deviation of degree of cure test results.

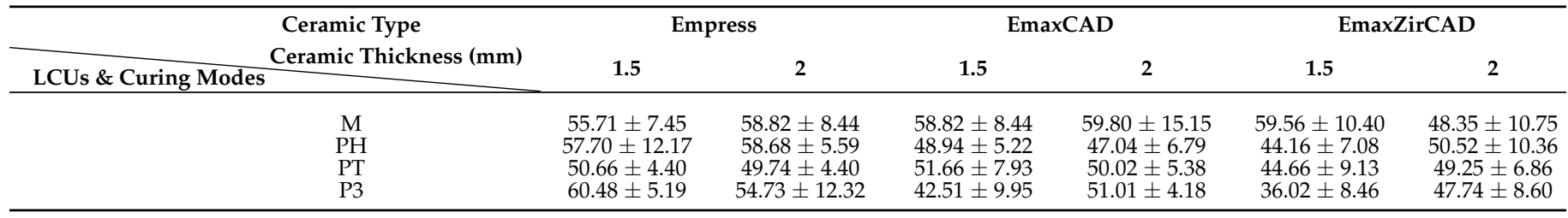




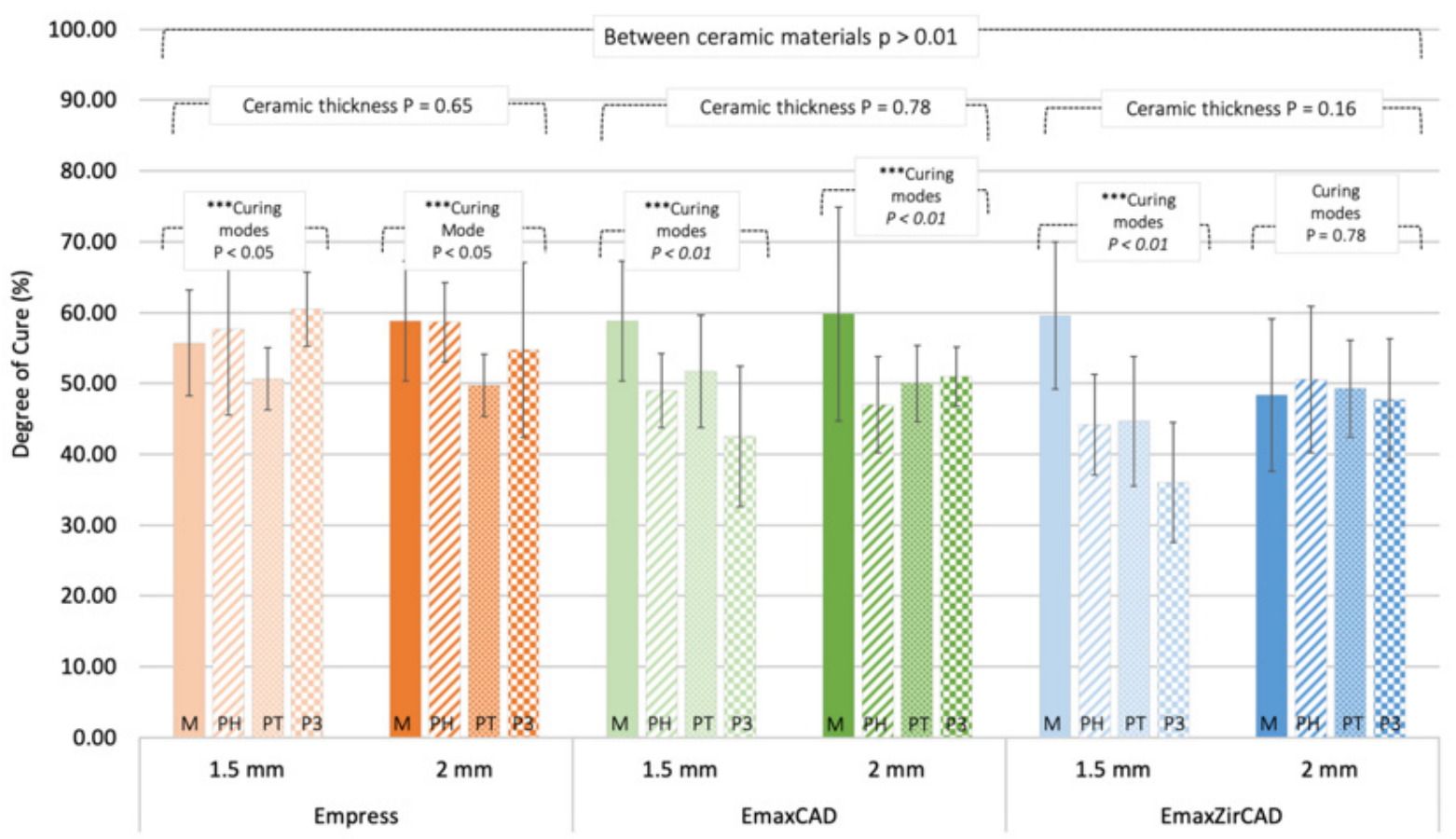

Figure 5. Bar chart plotting the mean and standard deviation of degree of cure (Empress-Leucitrereinforced; EmaxCAD-Lithium disilicate; EmaxZirCAD-Zirconia) (M-monowave; $\mathrm{PH}$-polywavehigh mode; PT-polywave-turbo mode; P3-polywave-3 s mode). ${ }^{* * *}$ indicates statistical significance $p<0.01$.

\subsection{Mode of Failure and Surface Analysis}

In this study, the mode of failure between different ceramic types varied. The empress group showed a predominantly mixed failure mode, with one group (Empress; $2.0 \mathrm{~mm}$; PT) showing purely cohesive failure (Figure 6). All groups in EmaxCAD demonstrated purely adhesive failures (Figure 7). Lastly, EmaxZirCAD $1.5 \mathrm{~mm}$ groups showed predominantly adhesive failure, while EmaxZirCAD $2.0 \mathrm{~mm}$ groups showed mainly mixed failures, regardless of the different types of LCUs and curing modes used (Figure 8).

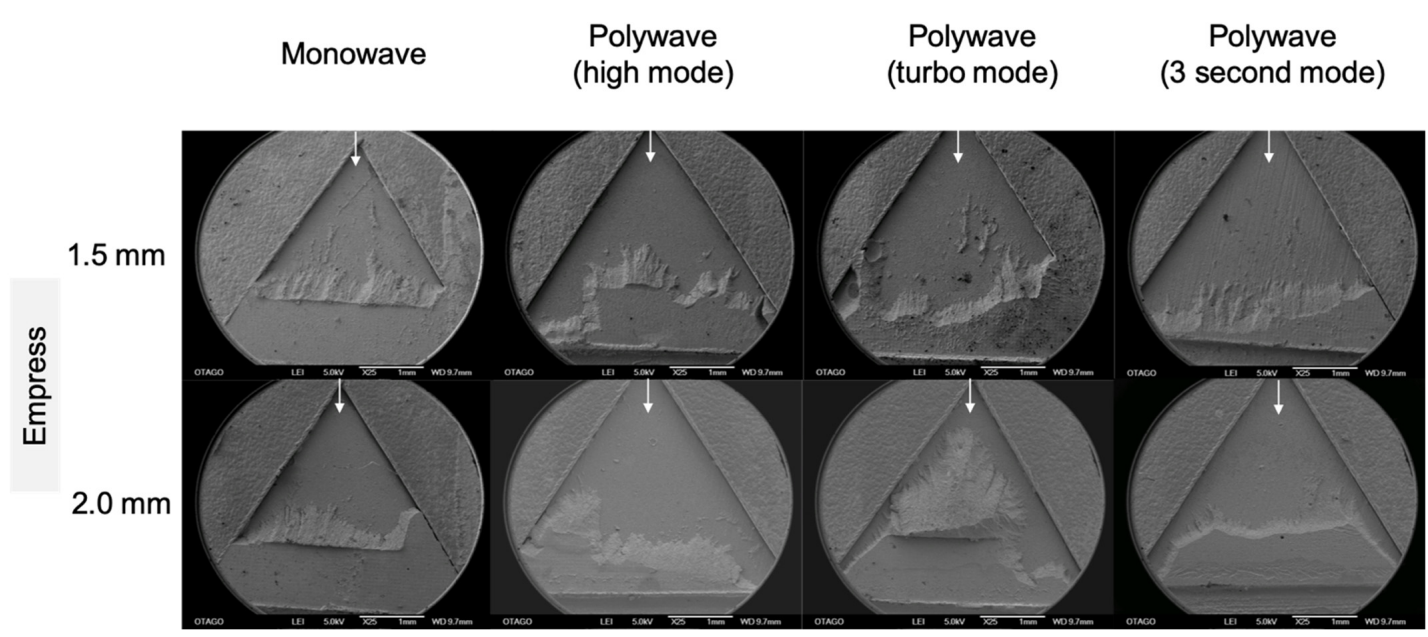

Figure 6. SEM images of bonded specimens between Empress and resin cement at $25 \times$ magnification to show overall mode of failure. The arrow is positioned at the tip of the chevron notch and shows the direction of crack propagation. 


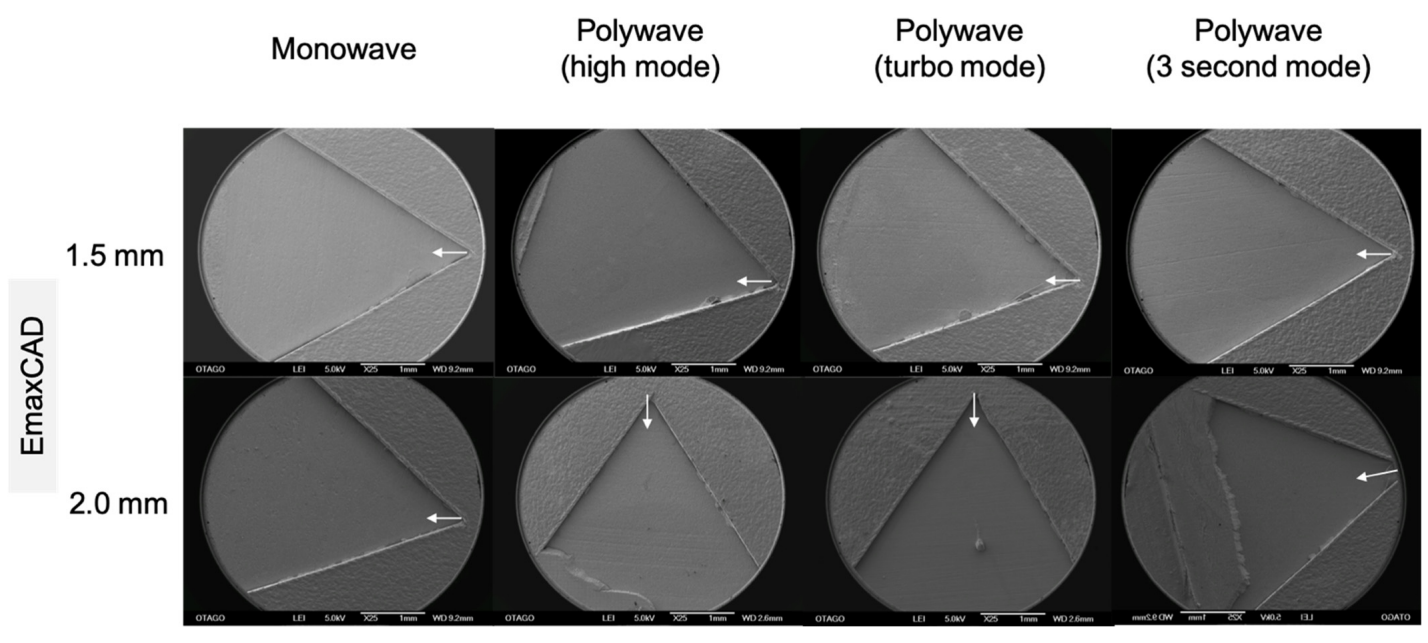

Figure 7. SEM images of bonded specimens between EmaxCAD and resin cement at $25 \times$ magnification to show overall mode of failure. The arrow is positioned at the tip of the chevron notch and shows the direction of crack propogation.

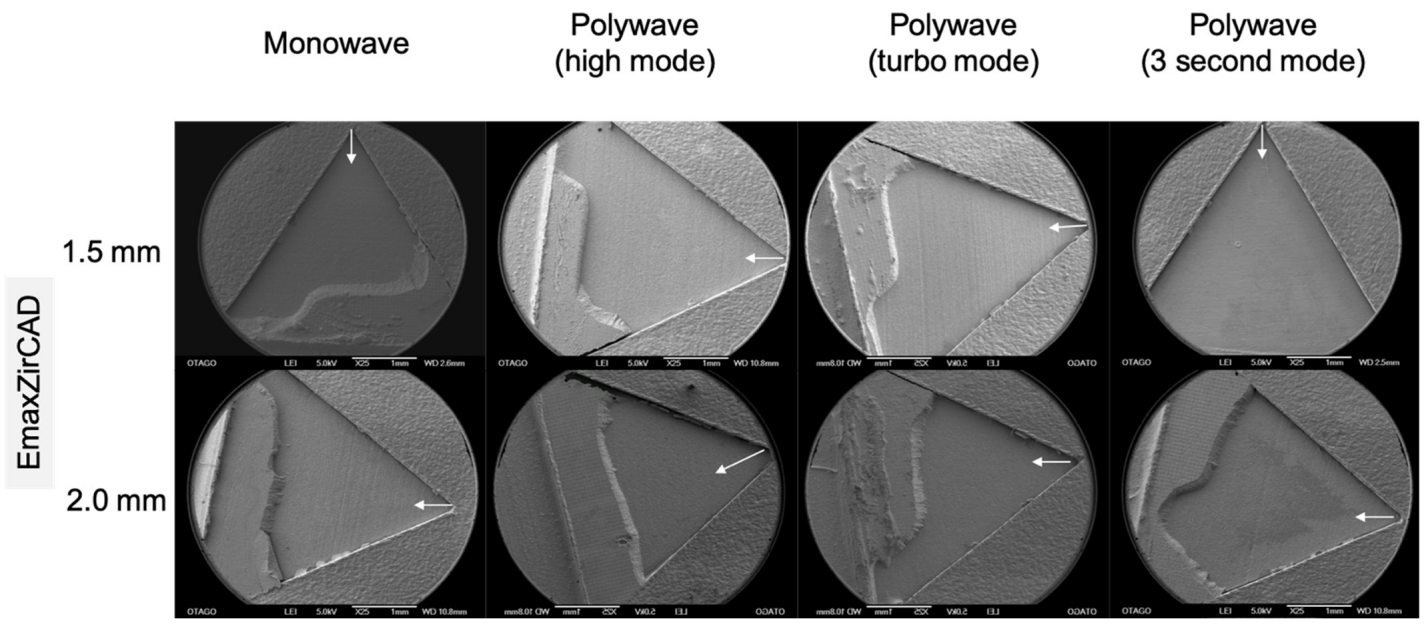

Figure 8. SEM images of bonded specimens between EmaxZirCAD and resin cement at $25 \times$ magnification to show overall mode of failure. The arrow is positioned at the tip of the chevron notch and shows the direction of crack propogation.

\section{Discussion}

The bond strength test results demonstrate that there was a significant decrease from Empress, EmaxCAD, and lastly, EmaxZirCAD. This variation in bond strength amongst different ceramic types is most likely due to its dissimilarity in material composition and microstructure, which has an impact on its optical properties [7]. According to a study by Pacheco et al. (2018), the increase in crystalline density can result in lower light transmission and increased light-scattering [28]. Empress is a glass-matrix ceramic consisting of 35-50\% leucite crystals by volume that are homogeneously imbedded into a glassy matrix [29]. Emax CAD is also a glass-matrix ceramic, but is composed of a greater crystalline density ( $70 \mathrm{vol} \%)$ of randomly-orientated and elongated plate-like lithium disilicate crystals [29]. It is proposed that light transmission through lithium disilicate ceramic is greatly interrupted by its high volume and irregularities of its crystals [25], thus increasing light-scattering and reducing light transmission through the ceramic. Emax ZirCAD is a polycrystalline ceramic that does not contain a glass phase, resulting in a highly dense crystalline phase of $87-95 \%$ zirconium oxide [7]. The absence of a glass phase coupled with the high concentration of crystals in zirconia ceramic makes them appear less translucent and more opaque when 
compared to glass-matrix ceramics, leading to a further decline in light transmission [30]. In terms of DC, the use of different ceramic types did not lead to a significant effect on the percentage of polymerisation of resin cement. This is not corroborated by a study from Oh et al. (2018), who stated that there was a statistical difference between the DC of resin cement when light-cured through Empress and Emax [25]. DC results from Mendonça et al. (2019), showed that composition and shade of lithium disilicate and zirconia ceramics had an influence on dual-cured resin cement [30]. It was concluded that there was a positive correlation between the light transmittance and DC of resin cements [30]. However, the degree of cure values observed between the three ceramic types used in this study did not show a significant difference between one another.

The results from the present study showed that an increase in the thickness of ceramics can affect the interfacial bond strength between ceramic and resin cements. According to a study carried out by Barutcigil and Büyükkaplan (2020), the increase in thicknesses of ceramic significantly decreased the amount of polymerisation of light-cure resin cement, especially at $1.5 \mathrm{~mm}$ and above [19]. When light passes through the ceramic, much of it is lost by reflection, absorption and scattering, which may impair the final polymerisation of resin cement $[19,22,25,28]$. The current study showed that the ceramic thicknesses only had a significant influence in lithium disilicate's bond strength. In a clinical application, it could be considered critical to keep indirect restorations made out of lithium disilicate at a maximum of $2.0 \mathrm{~mm}$, as any increase of thickness will significantly affect its bond strength. However, the different thicknesses of ceramics also did not have a significant effect on the degree of cure of resin cement, concluding that the choice of LCU and curing modes should be considered when it comes to clinical applications.

One of the main differences between the monowave and polywave LCUs is their wavelength emission spectra. In the present study, higher bond strength was observed when light-cured with a polywave LCU, regardless of the curing mode used, compared to the monowave LCU. This is because contemporary resin cement contains new photoinitiators, such as Ivocerin, that is present in the resin cement used in this study, which are most sensitive to shorter wavelength of violet light between $380 \mathrm{~nm}$ and $410 \mathrm{~nm}$ [31,32]. The monowave LCU delivers a limited amount of light below $420 \mathrm{~nm}$, which makes it not ideal to activate photoinitiators that requires a shorter wavelength of light. In contrast, a polywave LCU emits a broader range of wavelength, covering photoinitiators that are sensitive to both blue and violet rays [14]. Chen et al. (2019) stated the importance of compatibility between wavelength spectral emission from LCUs and wavelength spectral absorption from photoinitiators that will lead to satisfactory bond strength [33]. However, this is not always true for the DC of resin cement. The addition of diodes that emit violet light can negatively affect the total amount of blue light present and reduce the overall uniformity of light emitted across the light-curing tip. Polywave LCU is known to demonstrate regions with "hot spots" of very bright light, and also regions with "cold spots" where there is little or no light coming from its light-curing tip [14,16]. This leads to areas where radiant exposure to cure resin material is inadequate, resulting in impaired polymerisation $[14,16]$. Violet light has also been shown to exhibit lower light penetration compared to blue light within indirect restorative materials [28]. Therefore, information obtained from other studies mentioned have supported the results of this current study where most groups generally show higher DC of resin cement when cured with monowave LCU compared to polywave LCU.

The order of irradiance from highest to lowest are P3 $\left(3000 \mathrm{~W} / \mathrm{cm}^{2}\right), \mathrm{PT}\left(2100 \mathrm{~W} / \mathrm{cm}^{2}\right)$, $\mathrm{M}\left(1470 \mathrm{~W} / \mathrm{cm}^{2}\right)$, and $\mathrm{PH}\left(1200 \mathrm{~W} / \mathrm{cm}^{2}\right)$, respectively. In theory, the energy released from the light source aid in the activation of the polymerisation process of resin cement [16]. However, the results show that the highest irradiance released by P3 does not lead to the highest bond strength. This is supported by a study from Faria-e-Silva and Pfeifer (2017), stating that using high-irradiance LCU with shorter exposure time actually reduces the degree of polymerisation of the resin cement [20]. The P3 curing mode releases high irradiance for only $3 \mathrm{~s}$, which leads to a marked drop in total energy that is not maintained 
above the minimum energy [34]. This leads to premature polymerisation, due to the low mobility and migration of free radicals, which compromises the degree of conversion of resin cement [35]. Studies have stated that exposure time is one of the most important parameters affecting the degree of polymerisation and micro-mechanical properties of resin cement, where a prolonged light-curing time increases irradiance through the ceramic material [18]. In this study, the groups with the longest curing times were $\mathrm{M}$ and $\mathrm{PH}$, which were both at $10 \mathrm{~s}$, respectively. When comparing these two alone, the $\mathrm{PH}$ usually resulted in a higher bond strength compared to $\mathrm{M}$. With the additional aspect that the irradiance of $\mathrm{PH}$ is lower than $\mathrm{M}$, it can be concluded that the wavelength of spectral emission in a LCU plays a crucial role in resin photopolymerisation.

Each ceramic type used in this study showed a relatively consistent mode of failure regardless of the change in ceramic thicknesses and LCUs or curing modes used. Therefore, the difference in mode of failure between these three ceramic types were dependent on its composition and microstructure, and also the surface treatment prior to bonding. The bonding protocol for each ceramic type was different due to the variation in composition. As mentioned earlier, Empress and Emax CAD ceramics have a glassy phase, which allow them to be acid-etched to dissolve its glass content to create an ideal surface for micromechanical retention. In contract, a reliable bond between resin cement and a polycrystalline ceramic such as zirconia is difficult to achieve because of its chemical inertness and lack of silica particles that makes etching impossible. The bond between EmaxZirCAD and resin cement depends on mechanical retention from sandblasting, and chemical bonding with a saline coupling agent was used.

Optimal retention can be achieved when adhesion, rather than the cohesive strength of resin cement is stronger, leading to higher overall interfacial bond strength $[36,37]$. The SEM analysis illustrated that representative samples from Empress groups shows mainly mixed and cohesive failures, which signifies that the adhesive interface between ceramic and resin cement is very strong. This reflects in the interfacial bond strength measured, which is the highest for Empress groups. Even though EmaxCAD had similar material in pre-treatment as Empress, the reason why EmaxCAD groups were purely adhesive-even with less bond strength compared to Empress-is because of its microstructure, which reduces the amount of light passing through the ceramic, thus decreasing the interfacial bond strength. EmaxZirCAD had mainly shown adhesive and mixed failures. However, it should be noted that in mixed failures, the cohesive failure is usually present at the lower third of the bonded area. This suggests that the specimen had mainly debonded between the ceramic-resin interface.

Under clinical situations, there are two interfaces involved during crown cementationthe ceramic/cement interface and cement/dentin interface. It would be of further interest to look at the influence of cement/dentin interfacial bond strength under different LCUs and curing modes in ongoing studies. Although there are numerous past studies which imply the use of dual-cure resin cement $[12,19,23,30,38,39]$, the current study standardised the use of light-cure resin cement from the same manufacturer to control the variables and better observe changes in bond strength. In order to standardise the distance between lightcuring tips and the ceramic, the specimens were light-cured through direct contact with the light-curing tip. Therefore, it should be noted that the light received by ceramic restoration in a clinical situation is less than what was received by specimens in this study. Clinicians should ensure that restorations are always light-cured in all directions to ensure optimal light polymerisation. With the same proposed experimental set-up, future studies can focus on dual-cure resin cement instead. In addition, it was also noticed that the time between debonding the specimens and testing for DC can vary amongst different types of ceramic used. As mentioned earlier in the results, the interfacial bond strength decreased from the Empress group to Emax ZirCAD group. This means that the time needed to debond the Empress group was longer compared to the Emax ZirCAD group, thus fluctuating the time of specimens being exposed to light from the surrounding environment to the moment the resin cement from the debonded specimen was tested for DC. Future studies can improve 
on this aspect by setting aside a group of specimens to be debonded by hand immediately after curing and testing its DC, while another set of specimens of the same ceramic type is cured and debonded using the universal machine to measure its interfacial bond strength, as performed in this study. By performing the tests separately for each ceramic type, the range of timing to debond specimens of different ceramic type will be independent from the $\mathrm{DC}$ results.

\section{Conclusions}

Within the limitations of the study, the following conclusions can be made:

1. Increasing translucency of ceramics results in higher bond strength, as evidenced by Leucite-reinforced (Empress) $>$ Lithium disilicate (Emax CAD) $>$ Zirconia (Emax ZirCAD) ceramics.

2. Increasing ceramic thickness lowers bond strength, which was especially significant in lithium disilicate ceramics.

3. The use of polywave LCU in curing through ceramics generally resulted in greater bond strength compared to monowave LCU.

4. The use of different curing modes had a significant effect on the degree of cure of resin cement.

Author Contributions: Conceptualization, E.M.J.P., J.N.W. and J.J.E.C.; methodology, E.M.J.P., J.N.W. and J.J.E.C.; formal analysis, E.M.J.P., J.N.W. and J.J.E.C.; investigation, E.M.J.P., J.N.W. and J.J.E.C.; resources, J.J.E.C.; data curation, E.M.J.P. and J.J.E.C.; writing-original draft preparation, E.M.J.P., J.N.W. and J.J.E.C.; writing—review and editing, E.M.J.P., J.N.W. and J.J.E.C.; supervision, J.N.W. and J.J.E.C.; project administration, J.J.E.C.; All authors have read and agreed to the published version of the manuscript.

Funding: This research received no external funding.

Institutional Review Board Statement: Not applicable.

Informed Consent Statement: Not applicable.

Data Availability Statement: Not applicable.

Acknowledgments: The authors thank Tom (Shiyao) Chen for his assistance with graphic figures and design of the testing jigs. We would also like to thank Liz Girvan for her assistance with preparing specimens for SEM analysis and Bernadette Hyland from Ivoclar Vivadent NZ for her assistance with materials and equipment.

Conflicts of Interest: The authors declare no conflict of interest for this study.

\section{References}

1. Christensen, G.J. Is the rush to all-ceramic crowns justified? J. Am. Dent. Assoc. 2014, 145, 192-194. [CrossRef] [PubMed]

2. Warreth, A.; Elkareimi, Y. All-ceramic restorations: A review of the literature. Saudi Dent. J. 2020, 32, 365-372. [CrossRef] [PubMed]

3. Zhang, Y.; Kelly, J.R. Dental ceramics for restoration and metal veneering. Dent. Clin. N. Am. 2017, 61, 797-819. [CrossRef] [PubMed]

4. Brunton, P.A.; Sharif, M.O.; Creanor, S.; Burke, F.J.T.; Wilson, N.H.F. Contemporary dental practice in the UK in 2008: Indirect restorations and fixed prosthodontics. Br. Dent. J. 2012, 212, 115-119. [CrossRef] [PubMed]

5. Brunton, P.A.; Ratnayake, J.; Loch, C.; Veerasamy, A.; Cathro, P.; Lee, R. Indirect restorations and fixed prosthodontics: Materials and techniques used by general dentists of New Zealand. Int. Dent. J. 2019, 2019, 5210162. [CrossRef] [PubMed]

6. Zafar, M.S.; Amin, F.; Fareed, M.A.; Ghabbani, H.; Riaz, S.; Khurshid, Z. Biomimetic aspects of restorative dentistry biomaterials. Biomimetics 2020, 5, 34. [CrossRef]

7. Bajraktarova-Valjakova, E.; Korunoska-Stevkovska, V.; Kapusevska, B.; Gigovski, N.; Bajraktarova-Misevska, C.; Grozdanov, A. Contemporary dental ceramic materials, A review: Chemical composition, physical and mechanical properties, indications for use. Maced. J. Med. Sci. 2018, 6, 1742-1755. [CrossRef]

8. Lawson, N.C.; Frazier, K.; Bedran-Russo, A.K.; Khajotia, S.; Park, J.; Urquhart, O. Zirconia restorations: An american dental association clinical evaluators panel survey. J. Am. Dent. Assoc. 2021, 152, 80-81.e2. [CrossRef]

9. Cadenaro, M.; Maravic, T.; Comba, A.; Mazzoni, A.; Fanfoni, L.; Hilton, T. The role of polymerization in adhesive dentistry. Dent. Mater. 2019, 35, e1-e22. [CrossRef]

10. Zhang, L.; Luo, X.P.; Tan, R.X. Effect of Light-cured resin cement application on translucency of ceramic veneers and light transmission of LED polymerization units. J. Prosthodont. 2019, 28, e376-e382. [CrossRef] 
11. Passos, S.P.; Kimpara, E.T.; Bottino, M.A.; Júnior, G.C.S.; Rizkalla, A.S. Bond strength of different resin cement and ceramic shades bonded to dentin. J. Adhes. Dent. 2013, 15, 461-466. [PubMed]

12. Novais, V.R.; Raposo, L.H.; Miranda, R.R.; Lopes, C.C.; Simamoto, P.C.J.; Soares, C.J. Degree of conversion and bond strength of resin-cements to feldspathic ceramic using different curing modes. J. Appl. Oral Sci. 2017, 25, 61-68. [CrossRef] [PubMed]

13. Wingo, K. A review of dental cements. J. Vet. Dent. 2018, 35, 18-27. [CrossRef]

14. Price, R.B.; Ferracane, J.L.; Hickel, R.; Sullivan, B. The light-curing unit: An essential piece of dental equipment. Int. Dent. J. 2020, 70, 407-417. [CrossRef] [PubMed]

15. Price, R.B.; Ferracane, J.L.; Shortall, A.C. Light-curing units: A review of what we need to know. J. Dent. Res. 2015, 94, 1179-1186. [CrossRef]

16. Rueggeberg, F.A.; Giannini, M.; Arrais, C.A.G.; Price, R.B.T. Light curing in dentistry and clinical implications: A literature review. Braz. Oral Res. 2017, 31 (Suppl. 1), e61. [CrossRef]

17. Gan, J.K.; Yap, A.U.; Cheong, J.W.; Arista, N.; Tan, C. Bulk-fill composites: Effectiveness of cure with poly- and monowave curing lights and modes. Oper. Dent. 2018, 43, 136-143. [CrossRef]

18. AlShaafi, M.M.; AlQahtani, M.Q.; Price, R.B. Effect of exposure time on the polymerization of resin cement through ceramic. J. Adhes. Dent. 2014, 16, 129-135.

19. Barutcigil, K.; Büyükkaplan, U. The effect of thickness and translucency of polymer-infiltrated ceramic-network material on degree of conversion of resin cements. J. Adv. Prosthodont. 2020, 12, 61-66. [CrossRef]

20. Faria, E.S.A.L.; Pfeifer, C.S. Effectiveness of high-power LEDs to polymerize resin cements through ceramics: An in vitro study. J. Prosthet. Dent. 2017, 118, 631-636.

21. Ilie, N.; Stawarczyk, B. Quantification of the amount of blue light passing through monolithic zirconia with respect to thickness and polymerization conditions. J. Prosthet. Dent. 2015, 113, 114-121. [CrossRef]

22. Sulaiman, T.A.; Abdulmajeed, A.A.; Donovan, T.E.; Ritter, A.V.; Lassila, L.V.; Vallittu, P.K. Degree of conversion of dualpolymerizing cements light polymerized through monolithic zirconia of different thicknesses and types. J. Prosthet. Dent. 2015, 114, 103-108. [CrossRef] [PubMed]

23. Turkoglu, P.; Sen, D. Evaluation of dual-cure resin cement polymerization under different types and thicknesses of monolithic zirconia. Biomed. Res. Int. 2019, 2019, 4567854. [CrossRef] [PubMed]

24. Caprak, Y.O.; Turkoglu, P.; Akgungor, G. Does the translucency of novel monolithic CAD/CAM materials affect resin cement polymerization with different curing modes? J. Prosthodont. 2019, 28, e572-e579. [CrossRef]

25. Oh, S.; Shin, S.-M.; Kim, H.-J.; Paek, J.; Kim, S.-J.; Yoon, T.H. Influence of glass-based dental ceramic type and thickness with identical shade on the light transmittance and the degree of conversion of resin cement. Int. J. Oral Sci. 2018, 10, 5. [CrossRef] [PubMed]

26. Duran, İ.; Kaleli, N.; Ural, Ç.; Kavut, İ. Evaluation of the light transmission of chairside polymer infiltrated hybrid ceramics in different shades and thicknesses. J. Appl. Biomater. Funct. Mater. 2019, 17, 2280800018807109. [CrossRef]

27. Cheng, Y.S.; Douglas, W.H.; Versluis, A.; Tantbirojn, D. Analytical study on a new bond test method for measuring adhesion. Eng. Fract. Mech. 1999, 64, 117-123. [CrossRef]

28. Pacheco, R.R.; Carvalho, A.O.; Andre, C.B.; Ayres, A.P.A.; de Sa, R.B.C.; Dias, T.M. Effect of indirect restorative material and thickness on light transmission at different wavelengths. J. Prosthodont. Res. 2019, 63, 232-238. [CrossRef]

29. Fu, L.; Engqvist, H.; Xia, W. Glass-ceramics in dentistry: A Review. Materials 2020, 13, 1049. [CrossRef]

30. Mendonca, L.M.; Ramalho, I.S.; Lima, L.; Pires, L.A.; Pegoraro, T.A.; Pegoraro, L.F. Influence of the composition and shades of ceramics on light transmission and degree of conversion of dual-cured resin cements. J. Appl. Oral Sci. 2019, 27, e20180351. [CrossRef]

31. Alkhudhairy, F.; AlKheraif, A.; Naseem, M.; Khan, R.; Vohra, F. Degree of conversion and depth of cure of Ivocerin containing photo-polymerized resin luting cement in comparison to conventional luting agents. Pak. J. Med. Sci. 2018, 34, 253-259. [CrossRef] [PubMed]

32. Delgado, A.J.; Castellanos, E.M.; Coelho Sinhoreti, M.A.; De Oliveira, D.C.R.S.; Abdulhameed, N.; Geraldeli, S. The use of different photoinitiator systems in photopolymerizing resin cements through ceramic veneers. Oper. Dent. 2019, 44, 396-404. [CrossRef]

33. Chen, Y.; Yao, C.; Huang, C.; Wang, Y. The effect of monowave and polywave light-polymerization units on the adhesion of resin cements to zirconia. J. Prosthet. Dent. 2019, 121, 549.e1-549.e7. [CrossRef] [PubMed]

34. Li, Q.; Lin, H.L.; Zheng, M.; Ozcan, M.; Yu, H. Minimum radiant exposure and irradiance for triggering adequate polymerization of a photo-Polymerized resin cement. Materials 2021, 14, 2341. [CrossRef] [PubMed]

35. Lanza, M.D.S.; Andreeta, M.R.B.; Pegoraro, T.A.; Pegoraro, L.F.; Carvalho, R.M. Influence of curing protocol and ceramic composition on the degree of conversion of resin cement. J. Appl. Oral Sci. 2017, 25, 700-707. [CrossRef] [PubMed]

36. Von Fraunhofer, J.A. Adhesion and Cohesion. Int. J. Dent. 2012, 2012, 951324. [CrossRef]

37. Li, R.; Ma, S.Q.; Zang, C.C.; Zhang, W.Y.; Liu, Z.H.; Sun, Y.C. Enhanced bonding strength between lithium disilicate ceramics and resin cement by multiple surface treatments after thermal cycling. PLoS ONE 2019, 14, e0220466. [CrossRef] 
38. Flury, S.; Lussi, A.; Hickel, R.; Ilie, N. Light curing through glass ceramics with a second- and a third-generation LED curing unit: Effect of curing mode on the degree of conversion of dual-curing resin cements. Clin. Oral. Investig. 2013, 17, 2127-2137. [CrossRef]

39. Flury, S.; Lussi, A.; Hickel, R.; Ilie, N. Light curing through glass ceramics: Effect of curing mode on micromechanical properties of dual-curing resin cements. Clin. Oral Investig. 2014, 18, 809-818. [CrossRef] 